\title{
RETARDATION OF PROGRESSION OF CHRONIC KIDNEY DISEASE THROUGH PHARMACOLOGICAL INTERVENTIONS
}

\section{Tirumalesh K, Harini Devi Nimmanapalli, Rajitha P M, Divya G, Mahesh Kalyan N, Siva Kumar Vishnubotla,}

1,3,4,5 Pharm.D, Krishna Teja Pharmacy College, Tirupati

${ }^{2}$ MD. Biochemistry, Assistant Professor, , SVIMS, Tirupati

${ }^{6}$ DM., Nephrology, Senior Professor, SVIMS, Tirupati.

Article Info: Received 25 October 2018; Accepted 17 December. 2018

Cite this article as: Tirumalesh, T., Harini Devi, N., Rajitha, P M., Divya, G., Mahesh Kalyan, N., \& Siva Kumar,V., (2018). RETARDATION OF PROGRESSION OF CHRONIC KIDNEY DISEASE THROUGH PHARMACOLOGICAL INTERVENTIONS. Journal of Biomedical and Pharmaceutical Research, 7(6).

DOI: https://doi.org/10.32553/jbpr.v7i6.562

Address for Correspondence: Harini Devi Nimmanapalli, Assistant Professor, Biochemistry, SVIMS, Tirupati Conflict of interest statement: No conflict of interest

\section{ABSTRACT:}

Objective: Chronic Kidney Disease (CKD) patients have multiple co-morbidities and complications, and are prescribed with large number of medications. Studies on therapeutic strategies to slow the chronic kidney disease progression in India are limited. Aim of the study: The present study was undertaken to evaluate retardation of progression of Chronic Kidney Disease through pharmacological interventions. Materials and Methods: This was a retrospective study conducted during 6 months period from August 2017 to January 2018 on 180 patients diagnosed with CKD Results: The present study found the mitigating effect of the pharmacotherapy on indicator parameters in reducing the progression of CKD for the DM-CKD and Non DM-CKD groups Conclusion: The findings of present study conclude that pharmacological interventions of Seven indicator parameters in the management of Diabetes mellitus, Anaemia, Hypertension, Hyperphosphatemia, Hyperuricemia, proteinuria and Metabolic acidosis was beneficial to slow the progression of renal disease in DM-CKD and Non DM-CKD patients.

Key words: Chronic kidney disease, pharmacological, intervention, Diabetes mellitus, progression.

\section{INTRODUCTION}

Chronic kidney disease (CKD) is a worldwide public health problem with increasing incidence and prevalence, poor outcomes and high cost for treatment due to co-morbidities and poly pharmacy ${ }^{1}$. CKD is widely prevalent non-communicable disease that progress toward end stage renal failure and is responsible for increasing morbidity in India ${ }^{2}$.
There is clear evidence from clinical studies that hypertension and proteinuria are the key players in the pathophysiology of CKD progression in humans. Other potential contributors include diabetes mellitus (DM), smoking, obesity, genetic background, anaemia, altered mineral homeostasis, dyslipidemia, oxidative stress and chronic inflammation ${ }^{3,4}$. Efficient control of blood pressure and minimization of proteinuria are 
the two most important measures to preserve residual kidney function. Other factors, such as good glycemic control, prevention and treatment of anaemia, dyslipidaemia, and disorders of mineral metabolism, have an experimental basis, although their clinical importance is less clear to date. CKD patients due to associated co-morbidities and complications are prescribed, with more number of medications, that might alter the rate of progression of decline in kidney function 5 . Because of the multiple medications, CKD patients are at higher risk of developing drug related problems. Due to the complex therapeutic regimen there might be a need of requiring frequent monitoring and follow up. Drug utilization changes by the physician, time period, disease conditions and population makes it important to study the intervention of the drug continuously over a period of time ${ }^{6}$. Drug utilization studies in CKD patients helps to understand and build evidence for the medication use. CKD patients need to take medicines lifelong which makes it is very important to study the prescribing trends on a regular basis. There is very limited evidence from India that studied the effect of pharmacological interventions that slows the progression of chronic kidney disease. Hence the present study was taken up for evaluating the retardation of progression of Chronic Kidney Disease through pharmacological interventions.

Materials and Methods: This was a retrospective study conducted during 6 months period from August 2017 to January 2018 in the Department of Nephrology at Sri Venkateswara institute of medical Sciences, Tirupati, Andhra Pradesh, India. The study included 180 patients diagnosed with CKD as per KDIGO guidelines ${ }^{7}$. Among them 90 were CKD patients with DM of either gender of age group above 18 years as first group and remaining 90 were CKD patients without DM of either gender of age group above 18 years as second group. In both the groups patients below age group of 18 years, pregnant and lactating women and CKD patients on dialysis were excluded. The study was conducted after obtaining approval from the institutional ethics committee (IEC number: 674) and written informed consent from the participants in the study was taken before sample collection. The suitable designed data collection form was used to collect all the necessary information to evaluate the progression with respect to the pharmacological interventions. Data was collected from patient medical record for the demographic details such as age, gender, diagnosis, co-morbid conditions, and number of medications per prescription, laboratory parameters and other relevant information. Past medical condition and medication history was obtained from patients or attenders. Laboratory parameter form was used to collect the patient laboratory values at different time intervals. Treatment chart form was used to collect the prescribed drugs at different time intervals.

Estimated Glomerular filtration rate [e GFR] was calculated based on following formulas: Modification of Diet in Renal Disease (MDRD) study equation ${ }^{8}$.

$\mathrm{GFR}=186 \times\left(\mathrm{S}_{\mathrm{Cr}}\right)^{-1.154} \times(\text { age })^{-0.203} \times(0.742$ if female) $\times(1.21$ if African-American)

Chronic Kidney Disease Epidemiology Collaboration (CKD-EPI) equation ${ }^{9}$.

$\mathrm{GFR}=141 \times \min \left(\mathrm{S}_{\mathrm{cr}} / \mathrm{K}, 1\right)^{\alpha} \times \max \left(\mathrm{S}_{\mathrm{cr}} / \mathrm{K}, 1\right)$ $1.209 \times 0.993^{\mathrm{Age}} \times 1.018$ [if female] $\times 1.159$ [if black].

Statistical analysis: Data was recorded on a predesigned proforma and entered using Microsoft excel worksheet (Microsoft Corp, Redmond, WA). Numerical data was expressed as mean \pm Standard deviation (SD). Categorical values were presented as counts and percentage. Mean values between two groups were compared by using unpaired t-test . Comparison across the groups for the three consecutive years was done by using the repeated measures of ANOVA (Analysis of 
Variance). A p value of $<0.05$ was considered statistically significant. The statistical software IBM SPSS Statistics Version 20.0 (IBM Corp Somers NY, USA) was used for data analysis.

Results: The present study evaluated medical records of 180 CKD patients for the last 3 consecutive years retrospectively for a period of 6 months. The 180 patients with CKD were further sub divided into two groups based on diabetes status. First group was 90 patients as DM-CKD Group and second group was 90 patients as Non DM-CKD Group.

Table 1: Comparison of means of the demographic data between the two study groups

\begin{tabular}{|l|l|l|}
\hline Variable & DM-CKD group & Non DM-CKD \\
\hline Age (years) & $62.27 \pm 10.03$ & $56.55 \pm 12.5$ \\
\hline Body mass index kg/m² & $26.15 \pm 4.59$ & $24.06 \pm 3.93$ \\
\hline Males (\%) & $55(61 \%)$ & $62(39 \%)$ \\
\hline Females (\%) & $35(68 \%)$ & $28(31 \%)$ \\
\hline
\end{tabular}

AGE DISTRIBUTION OF NON DM-CKD GROUP

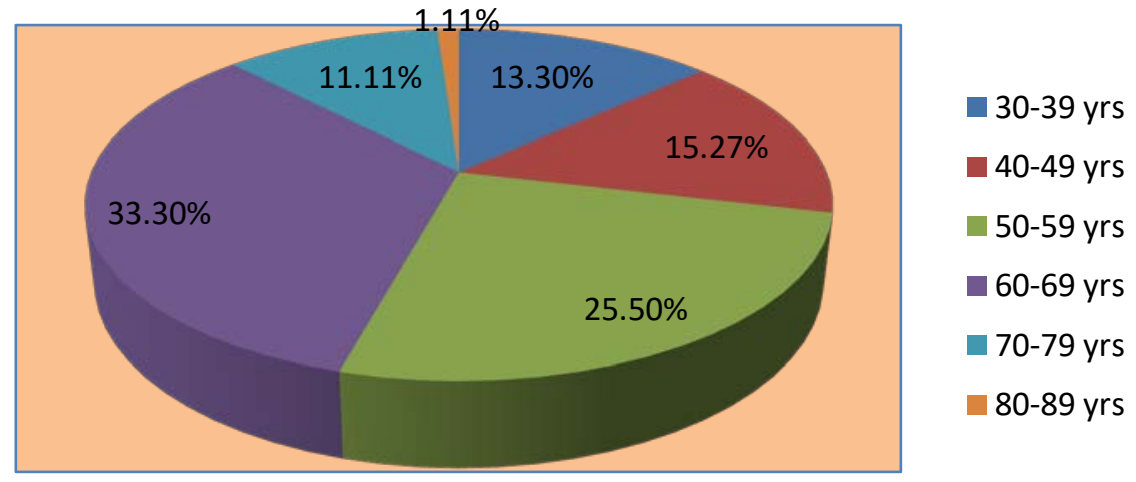

Figure 1: Age distribution of NON DM-CKD group

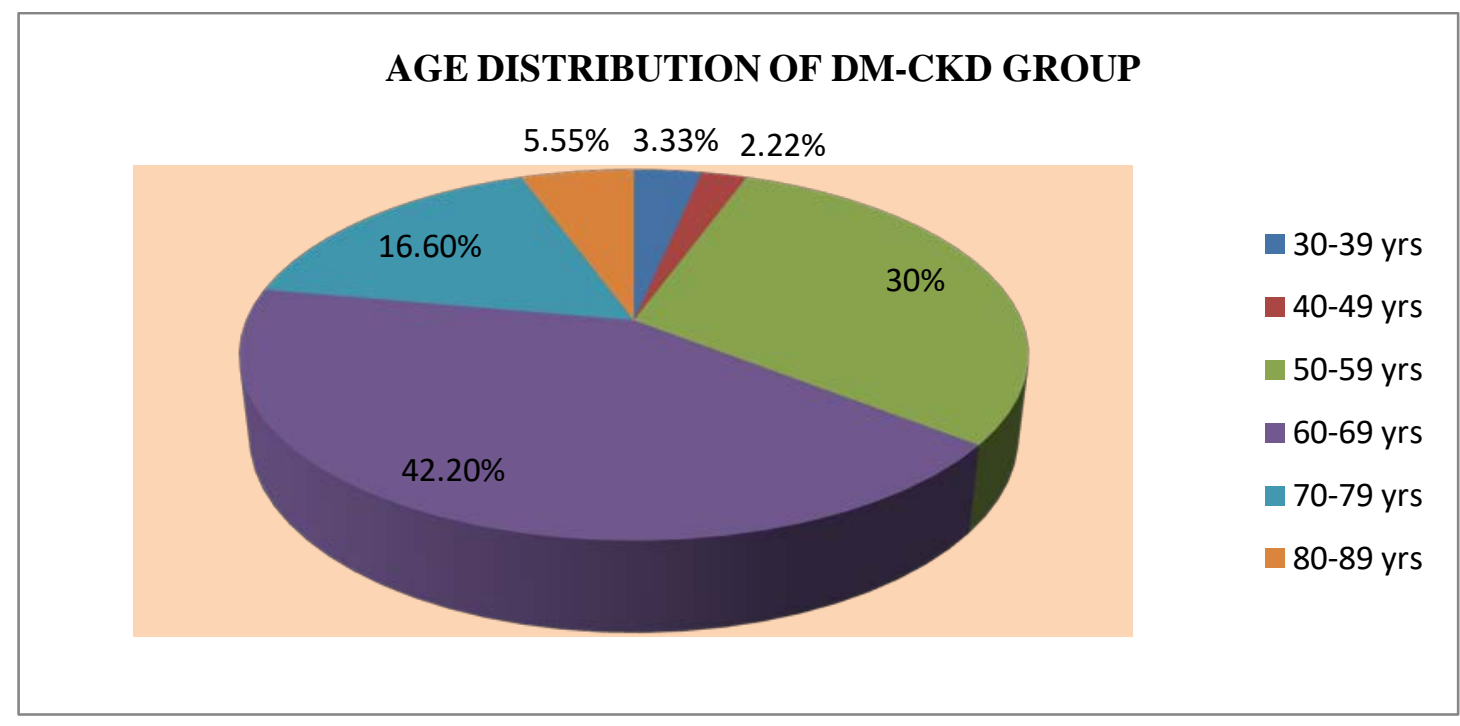

Figure 2: Age distribution of DM-CKD group 
Comparison of means of the demographic data between the two study groups was shown in table 1 \& figure 1 and 2. In DM-CKD group, 55 patients were males (61\%) and 35 patients were females (39\%). The mean age of patients was in the age group of $62.27 \pm 10.03$ years, mean body mass index was $26.15 \pm 4.59 \mathrm{~kg} / \mathrm{m}^{2}$ and mean body surface area was $1.70 \pm 0.16$ $\mathrm{m}^{2}$. In Non DM-CKD group, 62 patients were males (69\%) and 28 patients were females (31\%). The mean age of patients was in the age group of $56.55 \pm 12.5$ years, mean body mass index was $24.06 \pm 3.93 \mathrm{~kg} / \mathrm{m}^{2}$ and mean body surface area was $1.66 \pm 0.188 \mathrm{~m}^{2}$.

DM-CKD group:

Table 2: Comparison of means for the laboratory data in DM-CKD group during three consecutive years by using repeated measures ANOVA.

\begin{tabular}{|l|l|l|l|l|}
\hline Variable & $\mathbf{2 0 1 5}$ & $\mathbf{2 0 1 6}$ & $\mathbf{2 0 1 7}$ & p value \\
\hline FBS $(\mathrm{mg} / \mathrm{dL})$ & $123.00 \pm 41.00$ & $153.00 \pm 77.00$ & $149.00 \pm 75.00$ & $0.062^{\dagger}$ \\
\hline PPBS $(\mathrm{mg} / \mathrm{dL})$ & $210.00 \pm 63.00$ & $259.00 \pm 92.00$ & $229.00 \pm 93.00$ & $0.099^{\dagger}$ \\
\hline HbA1C $(\%)$ & $7.92 \pm 1.93$ & $8.44 \pm 2.76$ & $7.98 \pm 1.85$ & $0.775^{\dagger}$ \\
\hline e GFR MDRD $\left(\mathrm{ml} / \mathrm{min} / 1.73 \mathrm{~m}^{2}\right)$ & $31.78 \pm 14.59$ & $28.01 \pm 11.88$ & $25.82 \pm 13.45$ & $0.011^{*}$ \\
\hline e GFR CKD-EPI (ml/min/1.73m $\left.{ }^{2}\right)$ & $30.83 \pm 14.70$ & $29.16 \pm 24.76$ & $24.86 \pm 13.52$ & $0.082^{\dagger}$ \\
\hline Hb (gm/dL) & $11.8 \pm 1.87$ & $11.23 \pm 1.99$ & $11.31 \pm 1.84$ & $0.737^{\dagger}$ \\
\hline Blood pressure (mm of Hg) & $136 / 82$ & $135 / 82$ & $135 / 82$ & $0.847^{\dagger}$ \\
\hline S. Phos (mg/dL) & $3.9 \pm 0.84$ & $4.1 \pm 1.17$ & $4.2 \pm 0.88$ & $0.314^{\dagger}$ \\
\hline S. UA (mg/dL) & $5.8 \pm 1.77$ & $6.0 \pm 1.58$ & $5.5 \pm 2.14$ & $0.441^{\dagger}$ \\
\hline
\end{tabular}

FBS-Fasting blood sugar, PPBS-Post prandial blood sugar, HBA1C- Glycated haemoglobin, e GFRestimated glomerular filtration rate, $\mathrm{Hb}$ - Hemoglobin, Phos- Phosphorus, UA- Uric acid * Significant at the 0.05 probability level. ${ }^{\dagger}$ NS- Not significant at the 0.05 probability level.

Comparison of means for the laboratory data during the three consecutive years by using repeated measures ANOVA was shown in table 2. In the present study in the DM-CKD group mean e GFR according to MDRD equation was found to be $31.78 \pm 14.59 \mathrm{ml} / \mathrm{min} / 1.73 \mathrm{~m}^{2}$, $28.01 \pm 11.88 \mathrm{ml} / \mathrm{min} / 1.73 \mathrm{~m}^{2}$ and $25.82 \pm$ $13.45 \mathrm{ml} / \mathrm{min} / 1.73 \mathrm{~m}^{2}$ in the years 2015,2016 and 2017 respectively which was found to be stastically significant $\left(p=0.011^{*}\right)$. Mean e GFR according to CKD-EPI equation, was found to be $30.83 \pm 14.70 \mathrm{ml} / \mathrm{min} / 1.73 \mathrm{~m}^{2}, 29.16 \pm$ $24.76 \mathrm{ml} / \mathrm{min} / 1.73 \mathrm{~m}^{2}$ and $24.86 \pm 13.52$ $\mathrm{ml} / \mathrm{min} / 1.73 \mathrm{~m}^{2}$ in the years 2015,2016 and 2017 respectively which was found to be not stastically significant $(p=0.082)$.

In the present study insulin was the commonly prescribed anti-diabetic drug (50\%) for DM management. The other medications used were in the following order Glipizide (3.3\%), Glibenclamide (2.2\%), Acarbose (1.11\%), Voglibose (1.1\%) and Rosiglitazone (1.1\%) respectively. By using above pharmacological interventions the Fasting blood glucose (FBS) values were $123.00 \pm 41.00 \mathrm{mg} / \mathrm{dL}, 153.00 \pm$ $77.00 \mathrm{mg} / \mathrm{dL}$ and $149.00 \pm 75.00 \mathrm{mg} / \mathrm{dL}$ in the years 2015, 2016 and 2017 respectively. PPBS values were $210.00 \pm 63.00 \mathrm{mg} / \mathrm{dL}, 259.00 \pm$ $92.00 \mathrm{mg} / \mathrm{dL}$, and $229.00 \pm 93.00 \mathrm{mg} / \mathrm{dL}$ in the years 2015, 2016 and 2017 respectively. HbA1c values were $7.92 \pm 1.93,8.44 \pm 2.76$ and $7.98 \pm$ 1.85 in the years 2015, 2016 and 2017 respectively $(p=0.775)$.

In the present study for the Anaemia Management Erythropoietin stimulating agents [Darbepoetin alpha (22.2\%), epoetin alpha (16.6\%), epoetin beta $(16.6 \%)]$, iron supplements [IV iron sucrose $(7.7 \%)$, and oral elemental iron (27.7\%)] were used. By using 
above pharmacological interventions the $\mathrm{Hb}$ levels were found to be $11.8 \pm 1.87 \mathrm{~g} / \mathrm{dL}, 11.23$ $\pm 1.99 \mathrm{~g} / \mathrm{dL}, 11.31 \pm 1.84 \mathrm{~g} / \mathrm{dL}$ in the years 2015, 2016 and 2017 respectively, which was found to be not statistically significant $(p=$ 0.737).

In the present study for the Hypertension Management calcium channel blockers (CCB) [Amlodipine (71\%) nifedipine (7.77\%), cilindipine (5.55\%)], angiotensin receptor blockers (ARB) [Telmisartan (44.4\%)], beta blockers [Metoprolol (38.8\%)], centrally acting sympatholytics [Clonidine (5.55\%), Moxonidine (3.33\%)] and alpha blockers [Prazosin (20.22\%)] were used. By using above pharmacological interventions the systolic BP levels was found to be $136 \mathrm{~mm}$ of $\mathrm{Hg}, 135 \mathrm{~mm}$ of $\mathrm{Hg}$ and $135 \mathrm{~mm}$ of $\mathrm{Hg}$ in the years 2015, 2016 and 2017 respectively, and Diastolic BP levels was found to be $82 \mathrm{~mm}$ of $\mathrm{Hg}, 82 \mathrm{~mm}$ of $\mathrm{Hg}$ and $82 \mathrm{~mm}$ of $\mathrm{Hg}$ in the years 2015, 2016 and 2017 respectively, which was found to be not statistically significant ( $p=0.847$ for Systolic BP and $p=0.663$ for Diastolic BP]. In this group for the control of hypertension 28 patients $(31.1 \%)$, were using single drug, 27 patients (30\%), were using two drug combinations, 14 patients (15.55), were using three drug combinations and 4 patients (4.44\%), were using four drug combinations.

In the present study for the Hyperphosphatemia Management Calcium acetate (50\%) and Sevelamer (4.44\%) were used. By using above pharmacological interventions the phosphate levels were $3.9 \pm$ $0.84 \mathrm{mg} / \mathrm{dl}, 4.1 \pm 1.17 \mathrm{mg} / \mathrm{dl}$ and $4.2 \pm 0.88$ $\mathrm{mg} / \mathrm{dl}$ in the years 2015, 2016 and 2017 respectively, which was found to be not statistically significant $(p=0.314)$. In this group for hyperphosphatemia management 46 patients (51.1\%) were using single drug and 2 patients (2.22\%) were using two drug combinations.

In the present study for the Hyperuricemia Management Febuxostat (43.3\%) and Allopurinol (1.11\%) were used. By using above pharmacological interventions the uric acid levels were found to be $5.8 \pm 1.77 \mathrm{mg} / \mathrm{dl}, 6.0 \pm$ $1.58 \mathrm{mg} / \mathrm{dl}$ and $5.5 \pm 2.14 \mathrm{mg} / \mathrm{dl}$ in the years 2015, 2016 and 2017 respectively, well maintained in 3years duration without any significant change in the levels [ $p=0.441]$.

In the present study for the Proteinuria Management with Telmisartan and Ramipril mean value of $24 \mathrm{hrs}$ urinary protein levels was maintained in range of $899 \pm 200 \mathrm{mg} / 24 \mathrm{hrs}$. In Metabolic acidosis management 22 patients [24.4\%] were using single strength of sodium bicarbonate [500mg] and 62 patients [68.8\%] were using double strength of sodium bicarbonate [1000mg].

Non DM-CKD group:

Table 3: Comparison of means for the laboratory data in NON DM-CKD group during three consecutive years by using repeated measures ANOVA

\begin{tabular}{|l|l|l|l|l|}
\hline Variable & $\mathbf{2 0 1 5}$ & $\mathbf{2 0 1 6}$ & $\mathbf{2 0 1 7}$ & p value \\
\hline e GFR MDRD $\left(\mathrm{ml} / \mathrm{min} / 1.73 \mathrm{~m}^{2}\right)$ & $28.15 \pm 16.58$ & $28.05 \pm 15.91$ & $26.62 \pm 15.68$ & $0.394^{\dagger}$ \\
\hline e GFR CKD-EPI (ml/min/1.73m $\left.{ }^{2}\right)$ & $26.10 \pm 16.10$ & $26.40 \pm 13.95$ & $24.00 \pm 14.13$ & $0.447^{\dagger}$ \\
\hline $\mathrm{Hb}(\mathrm{gm} / \mathrm{dl})$ & $11.57 \pm 2.09$ & $11.68 \pm 2.33$ & $11.67 \pm 2.27$ & $0.945^{\dagger}$ \\
\hline Blood pressure (mm of Hg) & $133 / 83$ & $133 / 84$ & $130 / 82$ & $0.052^{\dagger}$ \\
\hline S. Phos (mg/dl) & $3.9 \pm 0.94$ & $3.86 \pm 0.74$ & $3.94 \pm 0.99$ & $0.881^{\dagger}$ \\
\hline S. UA (mg/dl) & $6.33 \pm 1.85$ & $6.26 \pm 2.02$ & $5.7 \pm 1.38$ & $0.140^{\dagger}$ \\
\hline
\end{tabular}

e GFR-estimated glomerular filtration rate, Hb- Hemoglobin, Phos- Phosphorus, UA- Uric acid

* Significant at the 0.05 probability level. ${ }^{\dagger}$ NS- Not significant at the 0.05 probability level. 
Tirumalesh K et al., Journal of Biomedical and Pharmaceutical Research

Comparison of means for the laboratory data in Non DM-CKD group during three consecutive years by using repeated measures ANOVA. In the present study in the Non DMCKD group mean e-GFR according to MDRD equation was found to be $28.15 \pm 16.58$ $\mathrm{ml} / \mathrm{min} / 1.73 \mathrm{~m}^{2}, 28.05 \pm 15.91 \mathrm{ml} / \mathrm{min} / 1.73 \mathrm{~m}^{2}$ and $26.62 \pm 15.68 \mathrm{ml} / \mathrm{min} / 1.73 \mathrm{~m}^{2}$ in the years 2015,2016 and 2017 respectively which was found to be not stastically significant ( $p$ $=0.394)$. Mean e-GFR according to CKD-EPI equation, was found to be $26.10 \pm 16.10$ $\mathrm{ml} / \mathrm{min} / 1.73 \mathrm{~m}^{2}, 26.40 \pm 13.95 \mathrm{ml} / \mathrm{min} / 1.73 \mathrm{~m}^{2}$ and $24.00 \pm 14.13 \mathrm{ml} / \mathrm{min} / 1.73 \mathrm{~m}^{2}$ in the years 2015,2016 and 2017 respectively which was found to be not stastically significant ( $p=$ 0.447).

In the present study for the NON DM-CKD Anaemia Management Erythropoietin stimulating agents [ESA] [Darbepoietin alpha (22.2\%), epoietin alpha (16.6\%), epoietin beta $(16.6 \%)$ ], iron supplements [IV iron sucrose (7.7\%) and oral elemental iron (27.7\%)] were used. By using above pharmacological interventions the $\mathrm{Hb}$ levels were found to be $11.57 \pm 2.09 \mathrm{~g} / \mathrm{dl}, 11.68 \pm 2.33 \mathrm{~g} / \mathrm{dl}$ and $11.67 \pm$ $2.27 \mathrm{~g} / \mathrm{dl}$ in the years 2015, 2016 and 2017 respectively well maintained in 3 years duration without any significant change ( $p=$ 0.945).

In the present study for the Non DM-CKD Hypertension Management CCB'S [Amlodipine (67.7\%), nifedipine (5.55\%), cilindipine (6.66\%)], ARB'S [Telmisartan (27.7\%)], Beta blockers [Metoprolol (25.5\%)], centrally acting sympatholytics [Clonidine (7.77\%), Moxonidine (3.33\%)] and Alpha blockers [Prazosin (20.55\%)] were used. By using above pharmacological intervention the systolic BP levels were found to be $133 \mathrm{~mm}$ of $\mathrm{Hg}, 133$ $\mathrm{mm}$ of $\mathrm{Hg} \& 130 \mathrm{~mm}$ of $\mathrm{Hg}$ in the years 2015, 2016 and 2017 respectively, and Diastolic BP were $83 \mathrm{~mm}$ of $\mathrm{Hg}, 84 \mathrm{~mm}$ of $\mathrm{Hg} \& 82 \mathrm{~mm}$ of $\mathrm{Hg}$ in the years 2015, 2016 and 2017 respectively, well maintained in 3 years duration without any significant change $(p=$ 0.052 for Systolic BP and $p=0.028$ for Diastolic BP). In this group for hypertension control 26 patients[28.88\%] were using single drug, 42 patients [46.6\%] were using two drug combination, 12 patients [13.33\%] were using three drug combination and 1 patients [1.11\%] were using four drug combination.

In the present study for the Non DM-CKD Hyperphosphatemia Management Calcium acetate $(51.1 \%)$ and Sevelamer (8.88\%) were used. By using above pharmacological interventions the phosphate levels were $3.9 \pm$ $0.94 \mathrm{mg} / \mathrm{dl}, 3.86 \pm 0.74 \mathrm{mg} / \mathrm{dl}$, \& $3.94 \pm 0.99$ $\mathrm{mg} / \mathrm{dl}$ in the years 2015, 2016 and 2017 respectively, but was found to be not significant $[p=0.881]$. In this group for Hyperphosphatemia management 44 patients [48.8\%] were using single drug and 5 patients [5.55\%] were using two drug combination.

In the present study for the Non DM-CKD Hyperuricemia Management Febuxostat (41.1\%) and Allopurinol (3.33\%) were used. By using above pharmacological interventions the uric acid levels were $6.33 \pm 1.85 \mathrm{mg} / \mathrm{dl}, 6.26 \pm$ $2.02 \mathrm{mg} / \mathrm{dl}$ and $5.7 \pm 1.38 \mathrm{mg} / \mathrm{dl}$ in the years 2015, 2016 and 2017 respectively, well maintained in 3 years duration but was found to be not significant $(p=0.140)$.

In the present study for the Non DM-CKD Protineuria Management with Telmisartan and Ramipril mean value of $24 \mathrm{hrs}$ urinary protein levels was maintained in range of $243 \pm 150 \mathrm{mg} / 24 \mathrm{hrs}$.

In the present study for the Non DM-CKD In Metabolic acidosis Management 35patients [38.8\%] were using Single strength of sodium bicarbonate [500mg] and 53patients [58.8\%] were using Double strength of sodium bicarbonate [1000mg].

In the present study annual GFR decline in DMCKD group according to MDRD equation was $6.00 \pm 1.10 \mathrm{ml} / \mathrm{min} / 1.73 \mathrm{~m}^{2}$ and CKD-EPI equation was $5.90 \pm 1.20 \mathrm{ml} / \mathrm{min} / 1.73 \mathrm{~m}^{2}$. In 
Tirumalesh $\mathrm{K}$ et al., Journal of Biomedical and Pharmaceutical Research

the present study annual GFR decline in Non DM-CKD group according to MDRD equation was $1.53 \pm 0.90 \mathrm{ml} / \mathrm{min} / 1.73 \mathrm{~m}^{2}$ and CKD-EPI equation was $2.60 \quad \pm 2.00$ $\mathrm{ml} / \mathrm{min} / 1.73 \mathrm{~m}^{2}$. These values are comparable to the reference article ${ }^{10}$ who reported an annual GFR decline of $5.8 \pm 3.0 \mathrm{ml} / \mathrm{min} / 1.73 \mathrm{~m}^{2}$. $(p=0.304)$ and $4.0 \pm 3.1(p=0.611)$ in DM-CKD and Non DM-CKD groups respectively as shown in table $4 \& 5$.

Table 4: Comparison of GFR decline in DM-CKD group and Non DM-CKD group in the present study

\begin{tabular}{|l|l|l|l|}
\hline Parameter & DM-CKD & Non DM-CKD & $p$ value \\
\hline e-GFR DECLINE BY MDRD & $6.00 \pm 1.10$ & $1.53 \pm 0.90$ & $0.001^{*}$ \\
\hline e-GFR DECLINE BY CKD-EPI & $5.90 \pm 1.20$ & $2.60 \pm 2.00$ & $0.001^{*}$ \\
\hline
\end{tabular}

Table 5: Annual GFR decline per year in DM-CKD and Non DM-CKD group compared to reference study

\begin{tabular}{|l|l|l|}
\hline Parameter & DM-CKD & Non DM-CKD \\
\hline $\begin{array}{l}\text { e GFR Decline } \mathrm{ml} / \mathrm{min} / 1.73 \mathrm{~m}^{2} \\
\text { MDRD (present study) }\end{array}$ & $6.00 \pm 1.10$ & $1.53 \pm 0.90$ \\
\hline $\begin{array}{l}\text { e GFR Decline CKD-EPI } \\
\left.\text { (present study) [ml/min/1.73m }{ }^{2}\right]\end{array}$ & $5.90 \pm 1.20$ & $2.60 \pm 2.00$ \\
\hline e GFR Decline from reference study ${ }^{[10]}$ & $5.8 \pm 3.0$ & $4.0 \pm 3.1$ \\
\hline P value & $0.304^{+}$ & $0.611^{+}$ \\
\hline
\end{tabular}

\section{Discussion:}

Pharmacological strategies which have been proven to slow the progression of diabetic and non-diabetic CKD are evaluated in the present study. In the present study annual GFR decline in DM-CKD group according to MDRD equation was $6.00 \pm 1.10 \mathrm{ml} / \mathrm{min} / 1.73 \mathrm{~m}^{2}$ and CKD-EPI equation was $5.90 \pm 1.20 \mathrm{ml} / \mathrm{min} / 1.73 \mathrm{~m}^{2}$. These values are comparable to the reference article (10) who reported an annual GFR decline of $5.8 \pm 3.0 \mathrm{ml} / \mathrm{min} / 1.73 \mathrm{~m}^{2} .(p=0.304)$. This is in line with a study by Kasiske et al $^{11}$.

In the present study annual GFR decline in Non DM-CKD group according to MDRD equation was $1.53 \pm 0.90 \mathrm{ml} / \mathrm{min} / 1.73 \mathrm{~m}^{2}$ and CKD-EPI equation was $2.60 \pm 2.00 \mathrm{ml} / \mathrm{min} / 1.73 \mathrm{~m}^{2}$. These values were compared with reference article values who reported annual GFR decline value $4.0 \pm 3.1 \mathrm{ml} / \mathrm{min} / 1.73 \mathrm{~m}^{2}$. The decline in
eGFR levels in the present study was significant when compared to reference e GFR decline $(p=0.611)$. It was observed that eGFR decline was more in DM-CKD group compared with Non DM-CKD group

In the present study in DM-CKD group HbA1c values were found to be $7.92 \pm 1.93,8.44 \pm$ 2.76 and $7.98 \pm 1.85$ in the years 2015, 2016 and 2017 respectively $(p=0.775)$. These findings are in line with the UKPDS study report which showed that in DM-CKD group, intensive glycaemic control produced better microvascular outcome with slowed CKD progression $^{12}$.

The anti-hypertensive treatment in CKD was shown to slow the progression of diabetic and non-diabetic renal disease in comparison to placebo group ${ }^{13,14}$. These findings are supported by the present study results which 
observed a well maintained BP status on antihypertensive treatment during the three years follow up and reduction in proteinuria.

In the present study all the phosphate binders have been found to be equally effective in terms of phosphate control if given in equivalent doses for the management of hyperphosphatemia in patients with CKD of both the groups ${ }^{15}$.

In the present study SUA was well maintained in three years period. Kanji et al suggested that allopurinol significantly reduces SUA levels, blood pressure, and statistically significant improvement in e GFR ${ }^{16}$. These findings are comparable to the present study findings.

In the present study, erythropoiesisstimulating agents for the treatment of anemia in patients with chronic kidney disease resulted in hemoglobin level of approximately 11. $0 \mathrm{~g} / \mathrm{dL}$ in both DM-CKD group and Non DMCKD group. This finding was in agreement to the recommended acceptable range of hemoglobin levels of $11.0-12.0 \mathrm{~g} / \mathrm{dL}$ for patients with chronic kidney disease as reported by Singh AK et al ${ }^{17}$.

In Chronic kidney disease, the progression is inexorable resulting in progressive decline in renal function which might be life threating to the patients. In such a situation optimistic control on the factors causing deterioration of renal function by enthusiastic and collaborative participation of the medical team brings out appreciable and beneficial outcomes to the patients. The present study high-lighted the mitigating effect of the pharmacotherapy on indicator parameters in reducing the progression of CKD in DM and Non-DM groups effectively. Hence shared decision-making is an integral component of this process and revisions to the care plan based on the changing needs and preferences of the patient and family must be considered ${ }^{18}$
Conclusion: The incidence and prevalence of CKD is increasing at an alarming rate, and it is unlikely that the economic resources and infrastructures might be able to meet this demand. At present, the best available evidence suggests that blood pressure and glycemic control will have the greatest impact on delaying the progression of both chronic kidney disease and cardiovascular disease. The present study evaluated pharmacological interventions of Seven indicator parameters in the management of Diabetes mellitus, Anaemia, Hypertension, Hyperphosphatemia, Hyperuricemia, proteinuria and Metabolic acidosis to slow the progression of renal disease in two groups of patients [DM-CKD \& Non DM-CKD] and found the beneficial role of pharmacotherapy to slow the future growth of ESRD. These findings also might conclude that pharmacotherapy must be instituted early in order to improve cardiovascular outcomes and potentially stabilise and retard the disease progression.

\section{References:}

1. Kappel J, Calissi P. Safe drug prescribing for patients with renal insufficiency. Can Med Assoc J 2002; 166:473-7.

2. Singh AK, Farag $Y M$, Mittal BV , Subramanian KK, Reddy SR, Acharya VN, et al. Epidemiology and risk Factors of chronic kidney disease in India - results from the SEEK (Screening and Early Evaluation of Kidney Disease ) study . BMC Nephrol 2013; 14: 1471-2369.

3. Abramson JL, Jurkovitz $\mathrm{CT}$, Vaccarino $\mathrm{V}$, Weintraub WS, McClellan W. Chronic Kidney Disease, anemia, and incident stroke in a middle-aged, community-based population: the ARIC study. Kidney Int. 2003; 64:610-15.

4. Francisco, A., \& Pinera, C. Challenges and future of renal replacement therapy. 2006; 10(s1):S19-S23.

5. Laporate JR, Orme ML. Drug utilization and the teaching of rational drug use. WHO Reg PublEur Ser 1993;45:183-91. 
6. Devi DP, George J. Diabetic Nephropathy: Prescription trends in tertiary care. Indian J Pharm Sci 2008;70:374.

7. Kidney Disease Improving Global Outcomes (KDIGO) CKD Work Group. Chapter 1: Definition and classification of CKD. Kidney Int Suppl 3; 2011. 2013.

8. Levey AS, Coresh J, Greene T, Stevens LA, Zhang $Y L$, Hendriksen $S$, et al. Using standardized serum creatinine values in the modification of diet in renal disease study equation for estimating glomerular filtration rate. Ann Intern Med 2006; 145(4):247-54.

9. Levey $A S$, Stevens LA, Schmid $\mathrm{CH}$, Zhang YL, Castro AF 3rd,Feldman HI, Kusek JW, Eggers $P$, Van Lente $F$, Greene $T$, Coresh J;CKD-EPI (Chronic Kidney Disease Epidemiology Collaboration):A new equation to estimate glomerular filtration rate.Ann Intern Med 2009;150(9):604-12.

10. Zoppini G, Targher G, Chonchol M, Ortalda V, Negri C, Stoico V, et al. Predictors of Estimated GFR Decline in patients with Type 2 Diabetes and Preserved Kidney Function. Clin J Am Soc Nephrol 2012; 7: 401-08.

11. Kasiske BL, Kalil RS, Ma JZ, Liao M, Keane WF. Effect of antihypertensive therapy on the kidney in patients with diabetes: A meta-regression analysis. Ann Intern Med 1993; 118:129-38.

12. UK Prospective Diabetes Study (UKPDS) Group. Intensive blood- glucose control with sulphonylureas or insulin compared with conventional treatment and risk of complications in patients with type 2 diabetes (UKPDS33). Lancet 1998;352:83753.

13. Jafar TH, Stark PC, Schmid $\mathrm{CH}$, Landa $\mathrm{M}$, Maschio G, de Jong PE, et al. Progression of chronic kidney disease: the role of blood pressure control, proteinuria, and angiotensin-converting enzyme inhibition. Ann Intern Med 2003;139:244-52.

14. Ruggenenti P, Perna A, Gherardi G, Garini G, Zoccali C, Salvadori $M$ et al. Renoprotective properties of ACEinhibition in non-diabetic nephropathies with non-nephrotic proteinuria. Lancet 1999;354:359-64

15. Navaneethan S.D, Palmer S.C, Vecchio M, Craig J.C, Elder G.J, Strippoli G.F. Phosphate binders for preventing and treating bone disease in chronic kidney disease patients. Cochrane Database Syst. Rev. 2011:CD006023

16. Kanji T, Gandhi M, Clase CM, Yang R: Urate lowering therapy to improve renal outcomes in patients with chronic kidney disease: systematic review and metaanalysis. BMC Nephrol 2015; 16: 58.

17. Singh AK, Szczech L, Tang KL, Barnhart $h$, Sapp S, Wolfson $M$ et al. Correction of anemia with epoetin alfa in chronic kidney disease. N Engl J Med 2006;355:2085-98.

18. Main J, Whittle C, Treml J, Wooley J, Main A. The development of an integrated care pathway for all patients with advanced life-limiting illness - the Supportive Care Pathway. J Nurs Manag 2006;14:521-8 